
http://ejurnal.uij.ac.id/index.php/CONS

\title{
MODEL BIMBINGAN KELOMPOK ISLAMI TEKNIK TRUTH OR DARE UNTUK MENINGKATKAN KEPRIBADIAN POSITIF SISWA SMA BANJARMASIN
}

\author{
Rusmilasari $^{1}$, Zainal Fauzi ${ }^{2}$, Akhmad Rizkhi Ridhani ${ }^{3}$ \\ ${ }^{1}$ Mahasiswa Prodi Bimbingan dan Konseling, FKIP, UNISKA MAB, Indonesia \\ ${ }^{2}$ Dosen Prodi Bimbingan dan Konseling, FKIP, UNISKA MAB, Indonesia \\ ${ }^{3}$ Dosen Prodi Bimbingan dan Konseling, FKIP, UNISKA MAB, Indonesia \\ E-mail: milasari.ms47@gmail.com , zainalf@uniska-bjm.ac.id , rizkhi.ridhani@gmail.com
}

\begin{abstract}
ABSTRAK
Tujuan penelitian ini: (1) mengetahui prosedur pengembangan model layanan, (2) mengetahui model layanan menurut akademisi dan praktisi. Penelitian ini menggunakan metode research and development (R\&D), dengan langkah-langkah sebagai berikut: (1) studi pendahuluan. (2) pengembangan model hipotetik. (3) validasi ahli. (4) revisi model. Berdasarkan validasi ahli Akademisi dan ahli Praktisi, dapat diketahui hasil validasi ahli Akademisi materi mendapat skor sebesar 29.5 atau sangat baik dan hasil validasi Praktisi dengan skor sebesar 22.2 atau baik serta dihasilkannya sebuah model layanan. Simpulan: kepribadian positif siswa sebelum diberikan layanan berada pada kategori rendah dan setelah diberikan layanan berada pada kategori tinggi.
\end{abstract}

Kata Kunci: Bimbingan Kelompok Islam, Teknik Truth or Dare, Kepribadian Positif

\begin{abstract}
The objectives of this research are: (1) knowing the procedure for developing service models, (2) knowing the service model according to academics and practitioners. This study uses a research and development (R\&D) method, with the following steps: (1) preliminary study. (2) development of a hypothetical model. (3) expert validation. (4) model revision. Based on the validation of Academic experts and Practitioners, it can be seen that the results of the validation of the material Academics got a score of 29.5 or very good and the results of Practitioner validation with a score of 22.2 or good and the result of a service model. Conclusion: The positive personality of students before being given service is in the low category and after being given the service it is in the high category.
\end{abstract}

Keywords: Group Guidance Islamic, Truth or Dare Technique, Positive Personality

Dipublikasikan Oleh : Program Studi Bimbingan dan Konseling FKIP Universitas Islam Jember 


\section{PENDAHULUAN}

Manusia merupakan ciptaan Allah yang paling sempurna dibandingkan makhlukmakhluk ciptaan-Nya yang lain Sesuai dalam firman Allah surat At-Tin ayat 04 yang berbunyi: "Sesungguhnya Kami telah menciptakan manusia dalam bentuk yang sebaik-baiknya". (Q.S At-Tin: 4). karena manusia memiliki akal budi, makhluk yang bermasyarakat, juga makhluk yang mempunyai sifat-sifat tersendiri yang khas dan unik. Setiap manusia selalu mempunyai sifat atau kepribadian tersendiri yang membedakannya dari manusia-manusia lainnya. Menurut Gregory \& Jess (2010:3) Kepribadian adalah suatu pola watak yang relatif permanen, dan sebuah karakter unik yang memberikan konsistensi sekaligus individualitas bagi perilaku seseorang. Sedangkan menurut Fromm dalam Alma (2013:78) kepribadian adalah merupakan keseluruhan kualitas psikis yang diwarisi atau diperoleh yang khas pada seseorang yang membuatnya unik. Berdasarkan pendapat para ahli di atas inti dari kepribadian adalah karakter yang dimiliki oleh seseorang yang membuatnya unik dan relatif permanen. Karakter kepribadian selalu mengikuti zaman, dan hidup pada masa itu.

Berdasarkan hasil pra penelitian yang dilakukan oleh peneliti pada hari jum'at tanggal 7 febuari 2020 dengan melakukan observasi dan pembagian angket DCM terhadap siswa di SMAN 13 Banjarmasin dalam hasil $\mathrm{dcm}$ yang telah dibagikan dan dianalisis sendiri oleh peneliti, menunjukkan fakta bahwa masih banyak siswa yang memiliki permasalahan pada kepribadian negatif yang terlihat dari siswa yang merasa kurang percaya diri karena prestasi akademiknya masih rendah di banding siswa-siswa lain, merendahkan dirinya sendiri, mengakui bahwa ucapan dan perbuatannya sering tidak sesuai dengan norma agama, bahkan banyak siswa yang merasa berdosa sekali. Terkikisnya kepribadian positif khususnya agama dan moral akan menimbulkan turunnya nilai kejujuran dalam kehidupan sehari-hari. Kebanyakan generasi remaja sekarang seolah menganggap kegiatan ibadah adalah suatu hal yang tidak terlalu penting dan cenderung menjadi orang yang lebih aktif di kegiatan yang kurang bermanfaat. Beberapa hal tersebut membuktikan bahwa segala permasalahan yang terjadi karena manusia jauh dari Allah SWT. Dalam hal ini keberadaan konselor atau guru bimbingan dan konseling sangat dibutuhkan untuk membantu siswa meningkatkan kepribadiannya. Salah satu bentuk upaya untuk meningkatkan kepribadian positif siswa adalah melalui layanan bimbingan kelompok bernuansa islam. Layanan bimbingan kelompok sebenarnya telah dilaksanakan oleh guru bimbingan dan konseling di SMA Negeri 13 Banjarmasin, namun dalam hal ini belum cukup optimal karena masih minimnya model dalam layanan bimbingan kelompok yang efektif bagi siswa. Oleh sebab itu, peneliti menggunakan layanan bimbingan kelompok bernuansa islam dengan teknik truth or dare untuk meningkatkan kepribadian positif.

Menurut Prasetiya (2020:3) Layanan bimbingan kelompok merupakan salah satu jenis layanan yang paling cocok digunakan untuk penanganan masalah yang sifatnya sama dan yang bermasalah lebih dari satu orang. Sedangkan Menurut Hanggara (2016:149) bimbingan kelompok merupakan pendekatan yang terstruktur dan efektif. 
Dengan tahap penyelenggaraanya yang relatif mudah dan sistematis memungkinkan untuk mengembangkan keterampilan tertentu yang dikehendaki. Dan menurut Rahmi Sofah (2014:25) Bimbingan Kelompok bernuansa islam adalah proses pemberian bantuan pada individu melalui kegiatan kelompok untuk secara bersama-sama memperoleh informasi keislaman dari narasumber atau konselor yang bermanfaat untuk kehidupan sehari-hari dengan memanfaatkan dinamika kelompok dan dengan cara memberdayakan iman, akal, dan kemauan yang dikaruniakan Allah Swt, mengajak anggota kelompok berpikir untuk menggali hikmah dalam setiap aktivitas dan mendalami kembali pemaknaan tentang konsep sabar, syukur, ikhlas, tawadhu, tawakal dan sebagainya dengan berlandaskan pada Al-Quran dan Hadist Rasulullah. Dalam pelaksanaan layanan bimbingan kelompok pada siswa nanti juga akan diterapkan suatu teknik. Salah satu teknik menarik dan inovatif yang dapat digunakan dalam membantu konseli adalah dengan menggunakan Teknik Truth or Dare. Penggunaan teknik dalam kegiatan bimbingan kelompok mempunyai banyak fungsi selain dapat lebih memfokuskan kegaiatan bimbingan kelompok terhadap tujuan yang ingin dicapai tetapi juga dapat membuat suasana yang terbangun dalam kegiatan bimbingan kelompok agar lebih bergairah dan tidak cepat membuat siswa jenuh mengikutinya, seperti yang dikemukakan oleh Romlah dalam gladding (2016) 'Bahwa teknik bukan merupakan tujuan tetapi sebagai alat untuk mencapai tujuan.
Dalam Indah Choirun Nisa (2017) menurut Schaefer (dalam Ma'unah: 2015) menyatakan bahwa, beberapa ahli seperti Abraham Maslow dan para ahli kepribadian lainnya seperti Adler, Sullivan, Erick Fromm dan Horney menegaskan bahwa fungsi kebersamaan dalam kelompok, khususnya dalam permainan, dapat membangun kepribadian yang lebih manusiawi, membentuk konteks sosial melalui minat sosial, membawa pada kebutuhan yang inheren dan mendorong untuk saling memiliki, terhindar dari isolasi, membangun kerjasama dan untuk mengurangi permasalahan hubungan interpersonal. Proses penelitian terdahulu yang dilakukan oleh Mutham Mimmah, (2015:14) bahwa peningkatan hasil belajar kognitif sains ipa fisika siswa dengan menerapkan media permainan truth or dare, hal ini dibuktikan berdasarkan analisis data penelitian dan pembahasan bahwa permainan truth or dare dapat membuat suasana belajar menyenangkan dan lebih baik daripada kelas yang tidak menggunakan permainan truth or dare. Daya serap belajar siswa adalah indeks atau tingkat pemahaman siswa dalam mempelajari, merespon dan mempraktikkan apa yang diajarkan, dibaca, didengar, dan dipelajarinya. Daya serap rata-rata siswa pada materi pokok bunyi dapat dilihat dengan persentase rata-rata daya serap siswa setelah perlakuan (menggunakan media permainan truth and dare) meningkat dibandingkan sebelum diberi perlakuan. Hasil penelitian ini menunjukkan bahwa pembelajaran menggunakan media permainan truth and dare dapat meningkatkan daya serap siswa. Hal ini disebabkan ada faktor yang mempengaruhi hasil belajar siswa yaitu faktor intern dan 
faktor ekstern. Faktor intren adalah faktor yang ada dalam diri individu yang sedang belajar. Yaitu secara psikologis (inteligensi, perhatian, minat, bakat, motivasi, kematangan dan kesiapan) dalam mengikuti proses pembelajaran serta kondisi siswa selama berlangsungnya kegiatan belajar mengajar.

Dengan berdasakan penjelasan diatas peneliti tertarik untuk melakukan penelitian dan pengembangan "model bimbingan kelompok bernuansa islam dengan teknik truth or dare untuk meningkatkan kepribadian positif siswa berlandaskan pada Al-qur'an dan Hadist. Penelitian ini diharapkan dapat menjadi solusi bimbingan yang dapat mengembangkan perilaku siswa kearah yang lebih baik dengan meningkatkan kepribadian positif siswa di sekolah.

\section{METODE}

Desain penelitian ini menggunakan penelitian dan pengembangan (research and development) Sugiyono (2012: 407) desain penelitian pengembangan atau dalam bahasa inggrisnya reseacrh and development adalah metode penelitian yang digunakan untuk menghasilkan produk tertentu, dan menguji keefektifan produk tersebut. Penelitian pengembangan diarahkan sebagai " a process used to develop and validase aducational product" Borg and Gall (2003 : 271). Produk yang dimaksud adalah model bimbingan kelompok bernuansa islami dengan teknik Truth or Dare untuk meningkatkan kepribadian positif siswa. Borg and Gall (2003:271) langkahlangkah yang seyogyanya di tempuh dalam penelitian pengembangan (research and develompment) meliputi : (1) studi pendahuluan. (2) perencanaan. pengembangan hipotetik. (4) penelaahan model hipotetik. (5) revisi (6) uji coba terbatas. (7) revisi hasil uji coba. (8) uji coba lebih luas. (9) revisi model akhir. (10) diseminasi dan sosioalisasi. Namun model penelitian dan pengembangan Borg and Gall ini penerapannya dalam pengembangan model bimbingan kelompok bernuansa Islami untuk meningkatkan kepribadian positif siswa tidak dilaksanakan sampai tahap diseminasi dan implementasi produk. Peneliti akan membatasi prosedur penelitian pengembangan sampai pada tahap kelima yaitu revisi. Penelitian ini memuat dua aspek, yaitu aspek pengembangan dan aspek riset. Aspek pengembangan diperoleh melalui pengembangan teknik truth or dare, sementara aspek riset terdapat pada konten layanan bimbingan kelompok bernuansa islami untuk meningkatkan kepribadian positif siswa. Penelitian dan pengembangan akan menghasilkan suatu produk yang layak dan menarik, serta lebih memungkinkan untuk diterapkan sebagai sumber acuan pelaksanaan bimbingan kelompok bernuansa islami untuk meningkatkan kepribadian positif siswa disekolah jika produk tersebut telah di validasi oleh ahli akademisi dan guru BK

\section{HASIL DAN PEMBAHASAN}

Hasil wawancara dan Observasi dari penelitian Pada bab ini, disajikan hasil penelitian dari pengembangan model bimbingan kelompok bernuansa Islam dengan teknik truth or dare untuk meningkatkan kepribadian positif siswa SMA Negeri di Banjarmasin. Hasil penelitian ini menyajikan data yang diperoleh dari pengumpulan data, prosedur pengembangan 
dan pembuatan produk serta hasil validasi oleh validator ahli akademisi dan validator praktisi.

Pengembangan model bimbingan kelompok bernuansa Islam dengan teknik truth or dare untuk meningkatkan kepribadian positif siswa SMA Negeri di Banjarmasin divalidasi oleh validator akademisi yang dilakukan di Fakultas Keguruan dan Ilmu Pendidikan Universitas Islam Kalimantan MAB oleh dosen yang berkompeten dibidang Bimbingan dan Konseling sedangkan validator praktisi adalah guru bimbingan dan konseling di SMA
Negeri Banjarmasin. Produk yang dikembangkan oleh peneliti divalidasi oleh dua orsng dosen ahli dan lima orang guru Bimbingan dan Konseling SMA Negeri di Banjarmasin. Validasi ini dilakukan untuk memperoleh data tentang prosedur dan kelayakan bentuk pengembangan model bimbingan kelompok bernuansa Islam dengan teknik truth or dare untuk meningkatkan kepribadian positif siswa SMA Negeri di Banjarmasin. Adapun data hasil validasi yang dijabarkan adalah sebagai berikut:

\section{Tabel 1. Hasil Perbaikan Model Bimbingan kelompok bernuansa Islam dengan teknik truth or dare untuk meningkatkan kepribadian positif siswa}

\begin{tabular}{|c|c|}
\hline Model Sebelum Perbaikan & Model Sesudah Perbaikan \\
\hline $\begin{array}{l}\text { Perlu ditambahkan paragraph } \\
\text { penekanan pendekatan/nilai } \\
\text { Islam pada bimbingan kelompok } \\
\text { baik ayat Al-Qur'an/hadist } \\
\text { bahwa pelaksanaan dakwah } \\
\text { juga berkelompok, termasuk } \\
\text { juga teknik yang digunakan } \\
\text { yaitu truth or dare nilai } \\
\text { Islamnya Sehingga tidak } \\
\text { panjang pengantar di awal } \\
\text { rasional, namun inti dari topic } \\
\text { inti pengembangan juga } \\
\text { semakin tegas nuansa Islamnya }\end{array}$ & $\begin{array}{l}\text { Sudah ditambahkan pada model terkait } \\
\text { penekanan nilai islam pada bimbingan } \\
\text { kelompok maupun tekniknya yaitu truth or } \\
\text { dare }\end{array}$ \\
\hline $\begin{array}{l}\text { Tujuan khusus belum terlihat } \\
\text { beda dengan tujuan umum, ini } \\
\text { bisa digambarkan harapan yang } \\
\text { ingin dicapai di sekolah tersebut } \\
\text { (tambah penjelasan setelah } \\
\text { dalil) }\end{array}$ & $\begin{array}{l}\text { sudah ditambahkan perbedaan tujuan } \\
\text { umum dan khusus serta penjelasan setelah } \\
\text { dalil }\end{array}$ \\
\hline $\begin{array}{l}\text { Bisa ditambahkan } 1 \text { paragrap } \\
\text { penjelasan perbidang }\end{array}$ & $\begin{array}{l}\text { Penjelasan perbidang sudah di tambahkan } \\
\text { dan di jelaskan }\end{array}$ \\
\hline $\begin{array}{l}\text { Pada halaman } 13 \text { sub } 1.6 .2 \text {. } \\
\text { Tahap Kegiatan, pada table } \\
\text { bagian a ada } 4 \text { pertemuan, } \\
\text { sedangkan sub bab } 1.8 .1 \text {. } \\
\text { Topik/Materi, Tujuan, dan }\end{array}$ & $\begin{array}{l}\text { Pada sub } 1.6 .2 \text { sudah ditambahkan kontrak } \\
\text { pertemuan agar sinkron dengan sub bab } \\
1.8 .1\end{array}$ \\
\hline
\end{tabular}


\begin{tabular}{lrr}
\hline Teknik ada 5 & materi, jadi & harap \\
sesuaikan & kalau & ada \\
hubungannya & pada & point \\
tersebut & & \\
\hline
\end{tabular}

Perlu diperhatikan lagi kesalahan dalam penulisan konjungsi dalam kalimat

\section{SIMPULAN}

Adapun kesimpulan dari penelitian ini ialah lahirnya sebuah model teruji satu yang dilalui dengan empat tahapan yakni; (1) Studi Pendahuluan; (2) Pengembangan Model Hipotetik; (3) Penelaahan Model Hipotetik; (4) Revisi Model Hipotetik. Selain dari pada itu tersusunya model bimbingan kelompok bernuansa Islam dengan teknik truth or dare secara utuh, dengan struktur yakni : Terdapatnya lima indikator dari masalah siswa (perkembangan moral dan nilai agama). Model bimbingan kelompok bernuansa Islam dengan teknik truth or dare ini memuat nilai-nilai agama yang bermanfaat bagi praktisi sekolah SMA Negeri di Banjarmasin dalam melaksanakan program kegiatan di SMA Negeri, khususnya di daerah Banjarmasin. Berdasarkan validasi ahli Akademisi dan ahli Praktisi, dapat diketahui hasil validasi ahli Akademisi materi sebesar 29.5 atau sangat baik dan hasil validasi Praktisi sebesar 22.2 atau baik.

Hasil wawancara dengan guru dan siswa secara keseluruhan menunjukkan tanggapan yang baik terhadap model bimbingan kelompok bernuansa Islam dengan teknik truth or dare. Namun peneliti menyadari bahwa model ini masih jauh dari sempurna karena diperlukan uji coba secara terbatas untuk mengetahui efektifitas dan efisiensinya dari model bimbingan kelompok bernuansa Islam dengan teknik truth or dare
Sudah diperbaiki kesalahan dalam penulisan dalam kalimat dengan teliti untuk meningkatkan kepribadian positif siswa. Oleh sebab itu disarankan bagi peneliti selanjutnya agar dapat melakukan uji coba secara maksimal.

\section{DAFTAR PUSATAKA}

Alma, B. (2013). Kewirausahaan. Bandung: Alfabeta.

Borg and Gall. 2003. Education Research. New York. Allyn dan Bacon.

Feist, Jess dan Feist, Gregory.2010. Teori Kepribadian. Buku 2. Jakarta: Salemba Humanika.

Gladding, S. T. (2016). The creative arts in counseling

(5th ed.). Alexandria, VA: American

Counseling Association

Hanggara, G. S. (2016). Keefektifan "Proses Guru" untuk

Sebagai Teknik Bimbingan Kelompok Meningkatkan

Kemampuan

Pengambilan

Keputusan Karier Siswa SMK. Volume $(1)$ 148-157.

Mimmah, M. (2015). Peningkatan Hasil Belajar

Kognitif Sains IPA Fisika Siswa dengan Menerapkan Media Permainan Truth and

Dare. Di akses dari 
https://media.neliti.com/media/publica tions/2

6541-peningkatan-hasilbelajar-kognitif sains.pdf

Nisa, I. C. (2017). Pengaruh Layanan Bimbingan Kelompok Dengan Permainan Truth or Dare (jujur atau tantangan) Terhadap Kemampuan VIII Komunikasi Interpersonal Siswa Kelas SMP NEGERI 1 Mojo Kediri tahun Pelajaran 2017. Volume (1), 5-6.

Prasetiya, Y. T. (2020). Pengaruh Layanan Bimbingan

Kelompok Menggunakan Teknik Karyawisata

Terhadap Tanggung Jawab Belajar

Siswa Kelas

X Smk Pgri 2 Kediri Tahun Pelajaran
2019/2020. Skripsi, Universitas Nusantara

PGRI Kediri. Di akses dari

http://simki.unpkediri.ac.id/mahasiswa /file artikel/2020/14.1.01.01.0060.pdf.

Reska, Sofah, R \& Gani, S. (2014). Aplikasi layanan

bimbingan kelompok berbasis islam untuk siswa kelas

meningkatkan self esteem pada XI IPS SMA Negeri 1 indralaya. Jurnal 23-34. konseling komprehensif volume (1),

Sugiyono. (2012). Metode Penelitian Kuntitatif, Kualitatif Dan R\&D. Bandung: Alfabeta. 